\title{
Predictors of Metabolic Syndrome among Employees: A Study from Jordan
}

\author{
Bayan Ahmad Obeidat ${ }^{{ }^{*}}$, Eslam Khaled Alyyan Al-Shami ${ }^{1}$, Khalid K. Abdul-Razzak ${ }^{2}$, \\ Yousef Saleh Khader ${ }^{3}$ \\ ${ }^{1}$ Department of Nutrition and Food Technology, Faculty of Agriculture, Jordan University of Science and Technology, Irbid, Jordan; \\ ${ }^{2}$ Department of Clinical Pharmacy, Faculty of Pharmacy, Jordan University of Science and Technology, Irbid, Jordan; ${ }^{3}$ Department \\ of Public Health, Faculty of Medicine, Jordan University of Science and Technology, Irbid, Jordan. \\ Email: \{*obeidatb, kkalani\}@just.edu.jo, yousef.k@excite.com
}

Received February $11^{\text {th }}, 2012$; revised March 28 ${ }^{\text {th }}, 2012$; accepted April $6^{\text {th }}, 2012$

\begin{abstract}
Background: Metabolic syndrome (MetS) is a major health problem around the world including Jordan and it has received notable consideration from epidemiologists in the latest years. The objective of this study was to estimate MetS prevalence among employees and its associated factors including socio-demographic, lifestyle, and dietary. Methods: A total of 491 employees (344 men and 147 women aged 20 - 65 years) participated in this study. Data concerning fasting plasma glucose level, lipid profile, blood pressure, anthropometric measurements and 24-dietary recalls were obtained. Results: MetS prevalence was 36.3\% (38.7\% among men and 30.6\% among women). Multiple logistic regression analysis results showed that the odds ratio of MetS was increased in older ages (OR: 3.0; 95\% CI: 1.43 - 6.47; $p<0.01$ ) and smokers (OR: 2.6; 95\% CI: $2.58-4.22 ; p<0.01$ ). With elevation 1 unit in the body mass index (BMI), risk of MetS increased by $30 \%$ (95\% CI: $22.9 \%-38.4 \% ; p<0.01)$ and an increase $1 \mathrm{mg} /$ day in dietary iron intake, the risk of MetS increased 2.4\% (95\% CI: $0.07 \%-4.3 \% ; p<0.01$ ). Conclusions: MetS prevalence is considered to be high among Jordanian employees which highlights the urgent need to develop comprehensive national strategies for prevention and treatment of MetS.
\end{abstract}

Keywords: Metabolic Syndrome; Employees; Jordan; Lifestyle-Dietary Factors

\section{Introduction}

Metabolic Syndrome (MetS) is a grouping of various metabolic disorders described by hyperglycemia, hypertension, central obesity, and dyslipidemia [1] which well known to raise the risk for development cardiovascular diseases (CVD) and type 2 diabetes mellitus (DM-2) [2-4]. For this reason MetS is an important public health concern and its diagnosis and treatment could potentially prevent the development of chronic diseases that largely known to be the leading causes of mortality world wide.

Although the etiology of MetS is not entirely understood, research has suggested that insulin resistance, obesity, environmental factors and genetic predisposition, may play major role in its pathogenesis [5,6]. Even though the exact prevalence of MetS is unknown, research suggests that it is increasing at displeasing rate worldwide $[6,7]$ and varies depending on the definition used and ethnicity [8]. However limited research is available about MetS prevalence or its components among employees [9-12]. Studies showed that MetS

*Corresponding author. prevalence was differed according occupational type $[9,10,12]$. To our knowledge, the prevalence of MetS among Jordanian employees is unknown. Therefore, this prospective research was undertaken to determine the prevalence of MetS among Jordanian employees and to establish associated socio-demographic, lifestyle, and dietary risk indicators for the MetS in this population. Identifying these factors will help in developing an effective intervention that target employees to manage and prevent the development of MetS and CVD and DM-2.

\section{Subjects and Methods}

\subsection{Subject's Selection and Recruitments}

A cross-sectional study was conducted between June 2007 and December 2007 in one of the Jordanian university. A representative sample of 838 university employees was systematically selected, every third name, from a list of names for all employees. The selected potential participants received an announcement which briefly explained the objectives, significance, and the protocol of the study. A total of 513 employees were 
agreed to participate in the study. Of these, 22 participants either had missing anthropometric measurements or did not fast well prior to biochemical test. Informed written consent was obtained from each subject who was willing to participate in the study. Institutional Review Board Committee approved this study.

\subsection{Dietary Assessment and Socio-Demographic and Lifestyle Related Factors}

Dietary intake was assessed using 24-hour dietary recall for two days (weekday and weekend). Employees were instructed to remember and illustrate the food and beverages that consumed over the past 24 hours for two days. The dietary recalls were entered into a Computerized Nutrient Analysis Program (ESHA, version 7.71, USA). On the other hand, self-administered questionnaire was used to identify the socio-demographic and lifestyle related factors. The questionnaire was pilot tested by an employee's sample to examine its clarity.

\subsection{Anthropometric, Biochemical and Blood Pressure Measurements}

Height, weight, and Waist circumference (WC) were measured to the nearest $0.1 \mathrm{~cm}, 0.1 \mathrm{~kg}, 0.1 \mathrm{~cm}$, respectively. Body mass index (BMI) was calculated using height and weight measurements as $\mathrm{kg} / \mathrm{m}^{2}$.

About $10 \mathrm{ml}$ of venous blood samples was collected in heparinyzed test tubes after an overnight fast. Plasma was used to measure glucose (FPG), triglyceride (TG), total cholesterol (TC) and High density lipoproteincholesterol (HDL-C) were measured in Hitachi 902 autoanalyzer, Roche; Germany. Low-density lipoproteins cholesterol (LDL-C) was calculated using the Friedewald equation (LDL-C $=\mathrm{TC}-\mathrm{HDL}-\mathrm{C}-[\mathrm{TG} / 5]$ ). This equation was valid until the triglyceride concentration reach 400 $\mathrm{mg} / \mathrm{dl}$, but if its concentration was higher than $400 \mathrm{mg} / \mathrm{dl}$ then LDL-C was measured using auto-analyzer. The blood pressure (BP) of each employee was measured twice in the sitting position after 5-minute rest period using an oscillometric sphygmomanometer (type USM700GSi, Elquest Corporation, Chiba, Japan).

\subsection{MetS Definition}

According to the American Heart Association and the National Heart, Lung, and Blood Institute (AHA/NHLBI) criteria, the diagnosis of MetS was made when three or more of the following risk factors are present: a waist circumference $(\mathrm{WC}) \geq 102 \mathrm{~cm}(\geq 40$ inches) in men and $\geq$ $88 \mathrm{~cm}$ ( $\geq 35$ inches) in women, fasting plasma glucose (FPG) $\geq 100 \mathrm{mg} / \mathrm{dl}(5.55 \mathrm{mmol} / \mathrm{l})$ or on drug treatment for elevated glucose, systolic blood pressure (SBP) $\geq 130$ $\mathrm{mmHg}$ or diastolic blood pressure (DBP) $\geq 85 \mathrm{mmHg}$ or on antihypertensive drug treatment in a patient with a history of hypertension, fasting triglycerides (TG) $\geq 150$ $\mathrm{mg} / \mathrm{dl}(1.7 \mathrm{mmol} / \mathrm{l})$ or on drug treatment for elevated triglycerides, and HDL-C $\leq 40 \mathrm{mg} / \mathrm{dl}(1.0 \mathrm{mmol} / \mathrm{l})$ in men and $\leq 50 \mathrm{mg} / \mathrm{dl}(1.3 \mathrm{mmol} / \mathrm{l})$ in women or on drug treatment for reduced HDL-C [1].

\subsection{Data Analyses}

Data were analyzed using the Statistical Package for Social Sciences (SPSS, version 15.0, 2007, Chicago, IL). Chi-square $\left(\chi^{2}\right)$ was performed to test the differences in socio-demographic, lifestyle and dietary factors between employees who have MetS and who do not have MetS. Independent-samples $t$-test was performed to compare the means of continuous variables between employees who have MetS and who do not have MetS. Pearson's correlation coefficient was performed to examine the associations between nutrients intake and clinical indicators of MetS. Univariate and multivariate logistic regression analysis were carried out to examine the determinants of MetS among socio-demographic, lifestyle and dietary factors. Findings with a $p$-values of $\leq 0.05$ were considered to be statistically significant.

\section{Results}

A total of 491 employees (344 men and 147 women aged 20 - 65 years) participated in this study. The crude prevalence of MetS and its individual metabolic abnormalities are presented in Figure 1. The prevalence of MetS among Jordanian employees was 36.3\% and low HDL-C was the most common abnormality. Although the prevalence of MetS and abdominal obesity were not significantly differ between gender, men have high prevalence of hypertriglyceridemia, high BP, and high FPG level, whereas women have high prevalence of low HDL-C level $(p<0.05)$ (Figure 2).

MetS prevalence and its individual metabolic abnormallities among employees stratified by gender and age are summarized in Table 1. MetS prevalence was positively correlated with age in both genders. It increase from $20.6 \%$ in men aged 20 - 34 years to $61.4 \%$ in men aged $45-54$ years and then reduced to $53.3 \%$ in those aged 55 - 65 years, while in women MetS prevalence was $14.9 \%$ in $20-34$ years old and sustained to rise to $85.7 \%$ in 55 - 65 years age group. Among men, the prevalence of abdominal obesity, high BP, and high FPG were significantly increased with age, while the prevalence of hypertriglyceridemia were significantly increased from $30.5 \%$ to $55.4 \%$ among study population ages between 20 - 54 years and then reduced to $53.3 \%$ among those aged 55 - 65 years. Among women, the prevalence of abdominal obesity, hypertriglyceridemia, high BP, and high FPG level were significantly increased with age 
Table 1. Prevalence of metabolic syndrome and its individual abnormal components among the study population stratified by age and gender.

\begin{tabular}{|c|c|c|c|c|c|c|c|}
\hline \multirow{2}{*}{ Gender } & \multirow{2}{*}{ Age } & \multicolumn{5}{|c|}{ Metabolic Syndrome Components n (\%) } & \multirow{2}{*}{ MetS $^{\text {h }}$} \\
\hline & & Enlarge $\mathbf{W C}^{\mathrm{c}}$ & High TG $^{\mathrm{d}}$ & Low HDL-C ${ }^{\mathrm{e}}$ & High $\mathbf{B P} \mathbf{P}^{\mathrm{f}}$ & High FPG ${ }^{g}$ & \\
\hline \multicolumn{8}{|l|}{ Men } \\
\hline & $20-34$ & $62(47.3)$ & $40(30.5)$ & $61(46.6)$ & $54(41.2)$ & $9(6.9)$ & $27(20.6)$ \\
\hline & $35-44$ & $84(73.0)$ & $52(45.2)$ & $65(56.5)$ & $63(54.8)$ & $30(26.1)$ & $47(40.9)$ \\
\hline & $45-54$ & $69(83.1)$ & $46(55.4)$ & $46(55.4)$ & $57(68.7)$ & $36(43.4)$ & $51(61.4)$ \\
\hline & $55-65$ & $13(86.7)$ & $8(53.3)$ & $8(53.3)$ & $11(73.3)$ & $9(60.0)$ & $8(53.3)$ \\
\hline \multicolumn{2}{|c|}{$p$-value } & $<0.001$ & 0.002 & 0.411 & $<0.001$ & $<0.001$ & $<0.001$ \\
\hline \multicolumn{8}{|l|}{ Women } \\
\hline & $20-34$ & $30(44.8)$ & $4(6.0)$ & $40(59.7)$ & $12(17.9)$ & $5(7.5)$ & $10(14.9)$ \\
\hline & $35-44$ & 43 (79.6) & $8(14.8)$ & $35(64.8)$ & $20(37.0)$ & $8(14.8)$ & $18(33.3)$ \\
\hline & $45-54$ & $16(84.2)$ & $9(47.4)$ & 15 (78.9) & $8(42.1)$ & $5(26.3)$ & $11(57.9)$ \\
\hline & $55-65$ & $7(100.0)$ & $6(85.7)$ & $6(85.7)$ & $6(85.7)$ & $6(85.7)$ & $6(85.7)$ \\
\hline \multicolumn{2}{|c|}{$p$-value } & $<0.001$ & $<0.001$ & 0.286 & 0.001 & $<0.001$ & $<0.001$ \\
\hline
\end{tabular}

a Data given in this table represent the abnormal measures for employees; ${ }^{\mathrm{b}}$ Data presented as numbers and percent within parenthesis; ${ }^{\mathrm{c}}$ Enlarged WC, enlarged waist circumference ( $\geq 102 \mathrm{~cm}$ in men and $\geq 88 \mathrm{~cm}$ in women); ${ }^{\mathrm{d}}$ High TG, high triglycerides concentrations $(\geq 150 \mathrm{mg} / \mathrm{dl}$ or on drug treatment for elevated triglycerides); ${ }^{\mathrm{e}}$ Low HDL-C, low high density lipoprotein cholesterol concentrations $(\leq 40 \mathrm{mg} / \mathrm{dl}$ in men and $\leq 50 \mathrm{mg} / \mathrm{dl}$; in women or on drug treatment for reduced HDL-C); ${ }^{\mathrm{f}}$ High BP, elevated blood pressure (systolic blood pressure $\geq 130 \mathrm{mmHg}$ or diastolic blood pressure $\geq 85$; mmHg or on antihypertensive drug treatment in a patient with a history of hypertension); ${ }^{\mathrm{g}} \mathrm{High}$ FPG, elevated fasting plasma glucose ( $\geq 100 \mathrm{mg} / \mathrm{dl}$ or on drug treatment for elevated glucose); ${ }^{\mathrm{h}} \mathrm{MetS}$, metabolic syndrome is defined according to the AHA/NHLBI criteria.

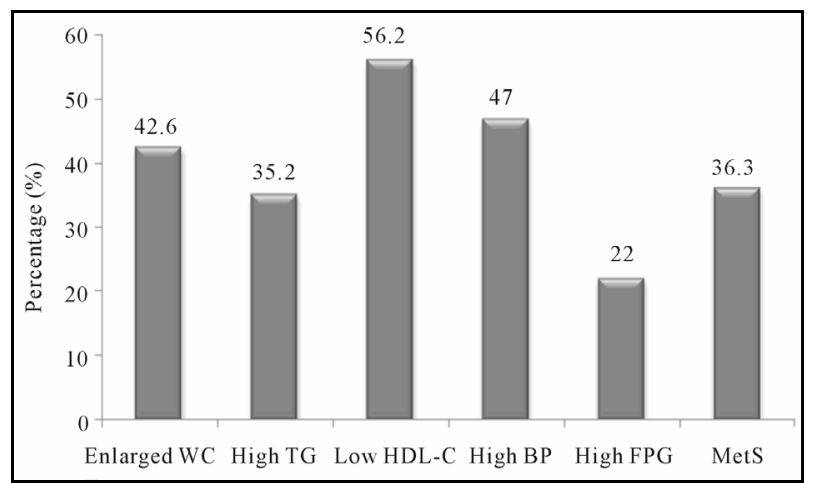

Figure 1. The prevalence of metabolic syndrome and its individual components among the study population. Enlarged WC, indicates enlarged waist circumference $(\geq 102 \mathrm{~cm}$ in men and $\geq 88 \mathrm{~cm}$ in women); High $\mathrm{TG}$, high triglycerides concentrations $(\geq 150 \mathrm{mg} / \mathrm{dl}$ or on drug treatment for elevated triglycerides); Low HDL-C, low high density lipoprotein cholesterol concentrations $(\leq \mathbf{4 0} \mathrm{mg} / \mathrm{dl}$ in men and $\leq \mathbf{5 0}$ $\mathrm{mg} / \mathrm{dl}$ in women or on drug treatment for reduced HDL-C); High BP, elevated blood pressure (systolic blood pressure $\geq$ $130 \mathrm{mmHg}$ or diastolic blood pressure $\geq 85 \mathrm{mmHg}$ or on antihypertensive drug treatment in a patient with a history of hypertension); High FPG, elevated fasting plasma glucose ( $\geq 100 \mathrm{mg} / \mathrm{dl}$ or on drug treatment for elevated glucose); and MetS, metabolic syndrome is defined according to the AHA/NHLBI criteria.

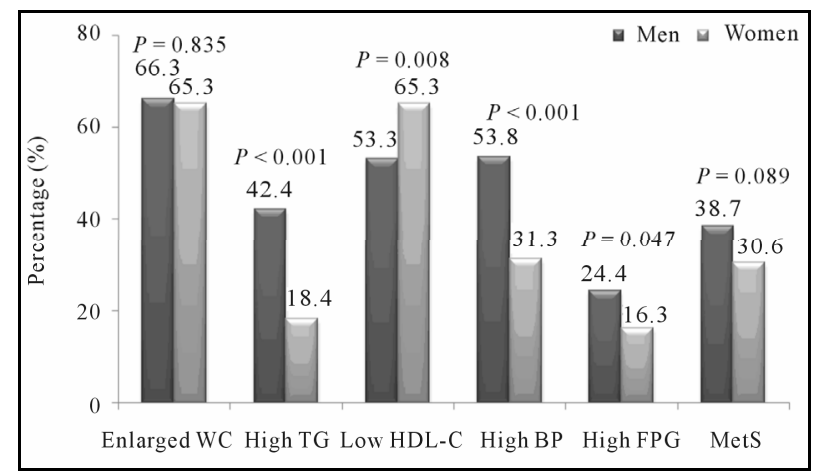

Figure 2. The prevalence of metabolic syndrome and its individual components among the study population stratified by gender.

among women. Women ages between 55 - 65 years had the highest prevalence of all the MetS components.

\subsection{General Characteristics and Lifestyle Behaviors of the Study Population and MetS}

MetS prevalence increased significantly with the increase in BMI (mean was $25.5 \pm 4.3 \mathrm{~kg} / \mathrm{m}^{2}$ for employees without MetS and $31.4 \pm 5.1 \mathrm{~kg} / \mathrm{m}^{2}$ for employees with MetS). Employees who were married, had large family size, had 
an income level $\geq 500 \mathrm{JD}$, had management jobs, and were smokers and physically inactive had high MetS prevalence. No associations were found in the educational level or living place. Data are shown in Table 2.

\subsection{Eating Patterns and Energy and Nutrients Intake of the Study Population and MetS}

No significant association was found between employees eating habits and behaviors and the prevalence of MetS except for using of olive oil and consumption of milk or yogurt as snack. Employees who reported that they used olive oil frequently had significantly lower MetS pre- valence $(33.0 \%)$ than employees who did not use it (43.2\%). Also employees who reported that they consumed milk or yogurt as snack had significantly lower prevalence of MetS (27.5\%) than employees who did not consume it as snack (38.3\%). Employees with MetS had significantly higher mean intake of calories, protein, and fat and some of the micro-nutrients than employees without MetS. However after adjustment for calories intake, all of these differences were not significant between employees with and without MetS except for iron intake. The mean intake of iron was higher among employees with MetS $(27.8 \pm 16.5 \mathrm{mg} /$ day; 28.5 for men

Table 2. General characteristics and lifestyle behaviors and the prevalence of the metabolic syndrome among the study population.

\begin{tabular}{|c|c|c|c|c|}
\hline \multirow{2}{*}{ Variable } & & \multicolumn{2}{|c|}{ Metabolic Syndrome n (\%) ${ }^{\mathrm{a}}$} & \multirow{2}{*}{ p-value } \\
\hline & & Absence & Presence & \\
\hline \multirow{4}{*}{ Body Mass Index (BMI) ${ }^{\mathrm{b}}$} & Under-weight & $9(100.0)$ & $0(0.0)$ & \multirow{4}{*}{$<0.001$} \\
\hline & Normal weight & $151(92.1)$ & $13(7.9)$ & \\
\hline & Over-weight & $118(65.2)$ & $63(34.8)$ & \\
\hline & Obese & $35(25.5)$ & $102(74.5)$ & \\
\hline \multirow{2}{*}{ Educational Level } & $<$ B.Sc. & $194(61.8)$ & $120(38.2)$ & \multirow{2}{*}{0.228} \\
\hline & $\geq$ B.Sc. & $119(67.2)$ & $58(32.8)$ & \\
\hline \multirow{2}{*}{ Marital Status } & Married & $204(56.8)$ & $155(43.2)$ & \multirow{2}{*}{$<0.001$} \\
\hline & Single & $109(82.6)$ & $23(17.4)$ & \\
\hline \multirow{3}{*}{ Income Level } & $<200$ JDs & $82(75.9)$ & $26(24.1)$ & \multirow{3}{*}{0.006} \\
\hline & 200 - 499 JDs & $169(62.1)$ & $103(37.9)$ & \\
\hline & $\geq 500 \mathrm{JDs}$ & $62(55.9)$ & $49(44.1)$ & \\
\hline \multirow{2}{*}{ Job Nature } & Management & $98(57.3)$ & $73(42.7)$ & \multirow{2}{*}{0.03} \\
\hline & Non-Management & $215(67.2)$ & $105(32.8)$ & \\
\hline \multirow{2}{*}{ Living Place } & City & $164(61.9)$ & $101(38.1)$ & \multirow{2}{*}{0.353} \\
\hline & Village & $149(65.9)$ & $77(34.1)$ & \\
\hline \multirow{3}{*}{ Family Size } & $<3$ People & $67(75.3)$ & $22(24.7)$ & \multirow{3}{*}{0.031} \\
\hline & 3 - 6 People & $152(62.8)$ & $90(37.2)$ & \\
\hline & $\geq 7$ People & $94(58.8)$ & $66(41.3)$ & \\
\hline \multirow{2}{*}{ Cigarette Smoking (current or past smokers) } & Yes & $139(57.2)$ & $104(42.8)$ & \multirow{2}{*}{0.004} \\
\hline & No & $174(70.2)$ & $74(29.8)$ & \\
\hline \multirow{2}{*}{ Physical Activity } & Doing & $134(70.9)$ & $55(29.1)$ & \multirow{2}{*}{0.009} \\
\hline & Not Doing & $179(59.3)$ & $123(40.7)$ & \\
\hline \multirow{3}{*}{ Transportation } & By Bus & $147(71.7)$ & $58(28.3)$ & \multirow{3}{*}{0.003} \\
\hline & By Car & $164(58.0)$ & $119(42.0)$ & \\
\hline & Both & $2(66.7)$ & $1(33.3)$ & \\
\hline
\end{tabular}

${ }^{\mathrm{a}}$ Data presented as numbers and percent within parenthesis; ${ }^{\mathrm{b}}$ Body mass index (BMI) classifications: underweight $\left(\mathrm{BMI}<18.5 \mathrm{~kg} / \mathrm{m}^{2}\right)$; normal weight $(\mathrm{BMI}$ between 18.5 and $24.9 \mathrm{~kg} / \mathrm{m}^{2}$ ); overweight (BMI between 25 and $29.9 \mathrm{~kg} / \mathrm{m}^{2}$ ); and obese (BMI > $30 \mathrm{~kg} / \mathrm{m}^{2}$ ); Notes: B.Sc., indicates bachelor degree; JDs: Jordanian Dinar, $1 \mathrm{JD}=1.25 \$$; Job nature: management job was for employees who were working as office workers, non-management job was for employees who were working as instructors, lab-technicians, maintainace workers, and farm workers. 
and 25.7 for women) than employees without MetS (21.4 $\pm 10.5 \mathrm{mg} /$ day; 23.4 for men and 17.8 for women) (data not shown). Pearson's correlation coefficients results reveled that the macronutrients and total energy intakes were significantly positively correlated with SBP, DBP, abdominal obesity, and BMI level, in contrast their intake were significantly negatively correlated with HDLC level (Table 3).

\subsection{Predictors of MetS among the Study Population}

Socio-demographic characteristics, lifestyle, and dietary factors that were significantly different between employees with and without MetS were considered in a univariate and multivariate logistic regression analysis to assess the potency of the relationship between these variables and MetS presence or absence (Table 4). In univariate logistic regression analysis, older age, mar- riage, higher income level, management jobs, large fam- ily size, smoking, higher BMI, higher iron intake, physi- cal inactivity and transportation by car were significant predictors of prevalent MetS. However when all of these variables were included in one multivariate model, age, smoking, BMI, and iron intake were the only significant predictors of prevalence of MetS. Results showed that employees with ages between 45 - 54 years were 3 times more likely to had MetS than younger employees with other age groups. Smokers employees were 2.6 times more likely to had MetS than non-smoker. Also for every increase of 1 unit in BMI, the risk of MetS increased $30.4 \%$ while for every increase $1 \mathrm{mg}$ /day in dietary iron intake, the risk of MetS increased 2.4\%.

\section{Discussion}

The finding of this study indicates the presence of high prevalence of MetS among Jordanian employees. Using the AHA/NHLBI definition of MetS, the prevalence of MetS in the present study was greatly higher than that documented by other studies among workers in Spain (9.5\%) [9], India (18.5\%) [11] and US (18.5\%) [12]. The high prevalence of MetS among Jordanian employees was expected since the prevalence MetS among population who live in northern Jordan found to be (43.7\%) [13], even was much higher than that reported in other developing and developed countries [13]. The variation in the prevalence of MetS between studies may be due to differences in definition used and target workers. Also the high MetS prevalence in the study population may be as a result of the increased prevalence of obesity, food overconsumption, inappropriate lifestyle behaviors such as smoking and physical inactivity and environmental factors such as stress related to work condition.

In agreement with many studies [9-18], this study showed that older age, postmenopausal status, higher BMI, and smoking history were associated with elevated chances of the MetS. Compared to the youngest age group (20 - 34 years), the prevalence rate in the 45 - 54 years age-group were about three times higher in men and about four times higher in women. Aging is normally accompanied by depletion of muscle mass and elevation of body fat, mainly in the abdomen region which could increase the incidence insulin-resistance [19]. In agreement with previous study, although the prevalence continued to rise in women at age group of 55 - 65 years to be about six times higher than the youngest age group, the prevalence in men declined in the same age group [13]. It has been suggested that MetS prevalence tend to decrease after the fifth decade in men because of the survival bias; people who had MetS may die at young age due to the occurrence of CVD and definitely reducing the older age category of affected people [13]. In contrast, menopause could be a contributing factor for the continuously increasing MetS prevalence with age in women which may result in visceral fat accumulation and insulin-resistance $[13,20]$.

The present study showed that approximately $37 \%$ of the employees were overweight, and $28 \%$ were obese. In comparing with normal weight employees, MetS prevalence was about four to five times higher in overweight employees and nine to ten times higher in obese employees. Interestingly the absence of MetS in under-

Table 3. Correlation coefficients for energy and macronutrients intakes and clinical characteristics of study population ${ }^{\mathrm{a}}$.

\begin{tabular}{ccccc}
\hline Clinical variable & Calories (Cal/d) & Protein (g/d) & Carbohydrate (g/d) & Fat (g/d) \\
\hline Fasting plasma Glucose (mg/dl) & $0.093^{*}$ & 0.017 & 0.033 & $0.128^{* *}$ \\
Triglyceride (mg/dl) & $0.160^{* *}$ & $0.133^{* *}$ & $0.171^{* *}$ & 0.078 \\
HDL-C (mg/dl) & $-0.227^{* *}$ & $-0.165^{* *}$ & $-0.178^{* *}$ & $-0.183^{* *}$ \\
Systolic blood pressure (mmHg) & $0.268^{* *}$ & $0.178^{* *}$ & $0.195^{* *}$ & $0.232^{* *}$ \\
Diastolic blood pressure (mmHg) & $0.240^{* *}$ & $0.109^{*}$ & $0.164^{* *}$ & $0.236^{* *}$ \\
Waist circumference (cm) & $0.554^{* *}$ & $0.316^{* *}$ & $0.519^{* *}$ & $0.398^{* *}$ \\
\hline
\end{tabular}

${ }^{a}$ Data presented as $r$-values; ${ }^{*}$ Correlation is significant at the 0.05 level; ${ }^{* *}$ Correlation is significant at the 0.01 level. 
Table 4. Predictors of metabolic syndrome prevalence using logistic regression analysis ${ }^{\mathrm{a}}$.

\begin{tabular}{|c|c|c|c|c|}
\hline \multicolumn{2}{|c|}{ Variable } & \multicolumn{2}{|l|}{ Unadjusted OR $(95 \% \mathrm{CI})$} & \multirow[t]{2}{*}{ Adjusted $^{\mathrm{b}} \mathrm{OR}(95 \% \mathrm{CI})$} \\
\hline \multirow{4}{*}{ Age (years) } & $20-34$ & & Reference & \\
\hline & $35-44$ & $2.720(1.695-4.364)^{* *}$ & & $1.611(0.858-3.025)$ \\
\hline & $45-54$ & $6.745(3.952-11.510)^{* *}$ & & $3.040(1.429-6.466)^{* *}$ \\
\hline & $55-65$ & $7.615(2.977-19.480)^{* *}$ & & $2.027(0.587-7.003)$ \\
\hline \multirow{2}{*}{ Marital status } & Single & & Reference & \\
\hline & Married & $3.601(2.193-5.912)^{* *}$ & & $1.501(0.743-3.034)$ \\
\hline \multirow{3}{*}{ Income level } & $<200$ JDs & & Reference & \\
\hline & 200 - 499 JDs & $1.922(1.161-3.184)^{* *}$ & & $1.163(0.573-2.362)$ \\
\hline & 500 or more & $2.493(1.397-4.446)^{* *}$ & & $1.134(0.503-2.554)$ \\
\hline \multirow{2}{*}{ Job nature } & Non-Management & & Reference & \\
\hline & Management & $1.525(1.041-2.236)^{*}$ & & $1.083(0.658-1.784)$ \\
\hline \multirow{3}{*}{ Family size } & $<3$ People & & Reference & \\
\hline & 3 - 6 People & $1.803(1.043-3.118)^{*}$ & & $1.429(0.721-2.833)$ \\
\hline & 7 - 10 People & $2.138(1.203-3.801)^{* *}$ & & $1.530(0.719-3.254)$ \\
\hline \multirow{2}{*}{ Cigarette smoking } & No & & Reference & \\
\hline & Yes & $1.820(1.252-2.645)^{* *}$ & & $2.583(1.580-4.224)^{* *}$ \\
\hline BMI & & $1.328(1.255-1.405)^{* *}$ & & $1.304(1.229-1.384)^{* *}$ \\
\hline Iron intake (mg/day) & & $1.042(1.025-1.060)^{* *}$ & & $1.024(1.007-1.043)^{* *}$ \\
\hline \multirow{2}{*}{ Physical activity } & Yes & & Reference & \\
\hline & No & $1.674(1.135-2.470)^{* *}$ & & $1.274(0.783-2.072)$ \\
\hline \multirow{3}{*}{ Transportation } & By bus & & Reference & \\
\hline & By car & $1.839(1.252-2.702)^{* *}$ & & $1.509(0.906-2.514)$ \\
\hline & Both & $1.267(0.113-14.246)$ & & $1.256(0.069-22.949)$ \\
\hline
\end{tabular}

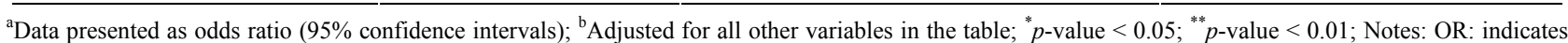
odds ratio from multiple logistic regression modeling; CI: confidence intervals; and BMI, body mass index.

weight employees was $100 \%$. The MetS and overweight or obesity have been associated with an increased risk of DM-2 and CVD morbidity and mortality, resulting in an enormous economic burden to societies [21-23]. Also in our study, smokers, either current or past, had higher MetS prevalence than non-smokers. Researchers suggested that cigarette-smoking might induce an increase in abdominal obesity, and elevate TG levels, lower HDL-C, and high BP [24,25].

As the employment period is considered as a time of nutritional stress that could contribute to latent dietary disturbance. In the presents study we focused on studying the effect of energy and nutrient intakes to estimate the effect of dietary factors on MetS prevalence. Results revealed that there were significant differences in many nutrient intakes between employees with and without
MetS. However, when total energy intake was adjusted, we observed that iron intake is the only nutrient that significantly differs between both groups. Employees with MetS consumed more dietary iron than employees without MetS. Therefore, our purpose for adjustment of the total calories intake was to prove our hypothesis that total calorie intake is the main cause of increased prevalence of MetS in our study population. We suggested that these observed differences in nutrient intakes between employees based on MetS status were mainly because of the overconsumption by our study population. We thought that our eating habits in Jordan that characterized by consumption of mixed dishes which most of the time contain all of the food groups, allow us to consume adequate amount or even more of macro- and micronutrients. However, our finding concerning iron intake is not un- 
expected. The association between iron level and atherosclerosis is an issue of debate for long period of time [26]. Iron has been well known to share in free radical producing reactions, thus the increased intake of iron leads to elevate the risk of oxidative stress state which in turn could lead to many diseases and abnormalities [27]. Although nearly all the body iron is protected by binding to the heme-containing proteins, high amount of stored iron in the body could be risky in existence of stimulants that disturbing iron homeostasis such as alcohol consumption or inflammatory status [27], however in our study ferritin level and the presence of inflammation were not examined. On the other hand, iron depletion because of menstruation could explain the low risk of CVD in women as well as it also explains the increased risk of CVD in menopause period [28]. Because of MetS is considered as a clustering of CVD risk factors, iron might be a contributable factor that increased risk of MetS among our study population. Unfortunately, our results were based on assessing dietary iron intake rather than its concentration in the body.

In the current study, the relation between macronutrients or total energy intake and different clinical characteristics was also examined. It has been well known that high-fat diets tend to be higher in saturated fat that mainly linked with the increase in serum total cholesterol (TC) and LDL-C concentrations which leads to development of CHD and in turn increased mortality rate [22], while high protein diets promotes phosphorus load, which can lead to acidosis and make worse insulin resistance [1]. Also very high carbohydrate intake was associated with dyslipidemia occurrence $[1,22]$. Importantly, the most harmful dietary factor we observed is high caloric intake because it considerably gathers all macronutrients that play a significant role in worsen the MetS status $[1,29]$. It has been documented that, a reduction of less than $10 \%$ body weight enhances insulin sensitivity, improves lipid profile and reduces BP [22,30]. Therefore emphasizing on weight reduction and healthy eating patterns with adequate caloric intake and well-distributed macronutrients ratios will be vital to improve the MetS status as well as decrease its prevalence among our population.

As the risk of developing elevated BP is estimated to be two to six times higher in overweight than in normal weight individuals [31], so it is not surprising that macronutrients as well as total calories intakes were positively associated with the elevation in both SBP and DBP. Research showed that the relationship between excess body weight and BP are proposed to be related to insulin resistance and hyperinsulinemia; elevated plasma insulin lead to increase renal sodium conservation and consequently BP elevation [32]. Although the direct relation between diet and HDL-C levels is controversial, high fat diet had a strong association with lower levels of HDL-C mainly the trans fatty acids [33-35]. Similarly as the serum levels of HDL-C are highly negatively associated with the TG levels so any factor increases the TG concentration will in turn lowers HDL-C concentration. Most importantly, as HDL-C, concentration is affected by weight gain; it will be affected by increased intake of all the macronutrients and total energy [1,22,34]. All of these facts could support our results for the inverse association between the HDL-C level and the macronutrients and total energy intakes.

There are several limitations to present study. First, the cross-sectional design does not allow us to make assumptions about the directional effect and causality, but it is considered as a valuable design that usually used in determining the prevalence. The study is also limited by the use of self-reports of dietary intake and physical activity levels. In addition, the stress level related to work was not assessed. On the other hand, the target population selection based on random samples from different kinds of jobs (instructors, lab-technicians, office workers, drivers, maintenance workers, and farm workers), as well as the inclusion of a representative sample of an employed population lived in different regions in Jordan constitutes one of the major strengths of our study.

\section{Conclusion}

Jordanian employees experience high prevalence of MetS. The odds ratio of MetS was significantly increased in older ages, current smokers, higher BMI, and higher daily dietary intake of iron. Clearly there is a great need for developing an effective countrywide intervention programs that target employees at high risk to manage the modifiable factors associated with MetS prevalence and preventing the consequences associated with this condition. In addition, cohort studies would serve as a complement to the present study to establish causality and directional effect of these factors.

\section{Acknowledgements}

The authors would like to thank the Deanship of Research at Jordan University of Science and Technology (JUST) for providing financial support for this project. Also the authors would like to thank the cooperation of all participants.

\section{REFERENCES}

[1] S. M. Grundy, J. I. Cleeman, S. R. Daniels, K. A. Donato, R. H. Eckel, B. A. Franklin, D. J. Gordon, R. M. Krauss, P. J. Savage, S. C. J. Smith, J. A. Spertus and F. Costa, "Diagnosis and Management of the Metabolic Syndrome. An American Heart Association/National Heart, Lung, and Blood Institute Scientific Statement," Circulation, 
Vol. 112, No. 17, 2005, pp. 2735-2752. doi:10.1161/CIRCULATIONAHA.105.169404

[2] S. Malik, N. D. Wong, S. S. Franklin, T. V. Kamath, G. J. L'Italien, J. R. Pio and G. R. Williams, "Impact of the Metabolic Syndrome on Mortality from Coronary Heart Disease, Cardiovascular Disease, and All Causes in United States Adults," Circulation, Vol. 110, No. 10, 2004, pp. 1245-1250. doi:10.1161/01.CIR.0000140677.20606.0E

[3] N. D. Wong, "Metabolic Syndrome: Cardiovascular Risk Assessment and Management," American Journal of Cardiovascular Drugs, Vol. 7, No. 4, 2007, pp. 259-172. doi:10.2165/00129784-200707040-00004

[4] T. N. Akbaraly, M. Kivimaki, M. L. Ancelin, P. Barberger-Gateau, T. Mura, C. Tzourio, J. Touchon, K. Ritchie and C. Berr, "Metabolic Syndrome, Its CompoNents, and Mortality In the Elderly," Journal of Clinical Endocrinology \& Metabolism, Vol. 95, No. 11, 2010, pp. E327-E332. doi:10.1210/jc.2010-0153

[5] P. Dandona, A. Aljada, A. Chaudhuri, P. Mohanty and R. Garg, "Metabolic Syndrome: A Comprehensive Perspective Based on Interactions between Obesity, Diabetes, and Inflammation," Circulation, Vol. 111, No. 11, 2005, pp. $1448-1454$.

doi:10.1161/01.CIR.0000158483.13093.9D

[6] K. D. Bruce and C. D. Byrne, "The Metabolic Syndrome: Common Origins of a Multifactorial Disorder," Postgraduate Medical Journal, Vol. 85, No. 1009, 2009, pp. 614621. doi:10.1136/pgmj.2008.078014

[7] H. Ashraf, A. Rashidi, S. Noshad, O. Khalilzadeh and A. Esteghamati, "Epidemiology and Risk Factors of the Cardiometabolic Syndrome in the Middle East," Expert Review of Cardiovascular Therapy, Vol. 9, No. 3, 2011, pp. 309-320. doi:10.1586/erc.11.9

[8] K. Khunti and M. Davies, "Metabolic Syndrome," British Medical Journal, Vol. 331, No. 7526, 2005, pp. 11531154. doi:10.1136/bmj.331.7526.1153

[9] M. A. Sánchez-Chaparro, E. Calvo-Bonacho, A. González-Quintela, C. Fernández-Labandera, M. Cabrera, J. C. Sáinz, A. Fernández-Meseguer, J. R. Banegas, L. M. Ruilope, P. Valdivielso and J. Román-García, "Ibermutuamur Cardiovascular Risk Assessment (ICARIA) Study Group. Occupation-Related Differences in the Prevalence of Metabolic Syndrome," Diabetes Care, Vol. 31, 2008, pp. 1884-1885.

[10] Y.C. Lin, T. J. Hsiao and P. C. Chen, "Persistent Rotating Shift-Work Exposure Accelerates Development of Metabolic Syndrome among Middle-Aged Female Employees: A Five-Year Follow-Up," Chronobiology International, Vol. 26, No. 4, 2009, pp. 740-755. doi:10.1080/07420520902929029

[11] C. V. Nair, "Metabolic Syndrome: An Occupational Perspective," Indian Journal of Community Medicine, Vol. 35, No. 1, 2010, pp. 122-124. doi:10.4103/0970-0218.62569

[12] E. P. Davila, H. Florez, L. E. Fleming, D. J. Lee, E. Goodman, W. G. LeBlanc, A. J. Caban-Martinez, K. L. Arheart, K. E. McCollister, S. L. Christ, J. C. Clark III and T. Clarke, "Prevalence of the Metabolic Syndrome among US Workers," Diabetes Care, Vol. 33, No. 11, 2010, pp. 2390-2395. doi:10.2337/dc10-0681

[13] Y. Khader, A. Bateiha, M. El-Khateeb, A. Al-Shaikh and K. Ajlouni, "High Prevalence of the Metabolic Syndrome among Northern Jordanians," Journal of Diabetes and Its Complications, Vol. 21, No. 4, 2007, pp. 214-219. doi:10.1016/j.jdiacomp.2005.11.003

[14] S. Zhu, M. P. St-Onge, S. Heshka and S. B. Heymsfield, "Lifestyle Behaviors Associated with Lower Risk of Having the Metabolic Syndrome," Metabolism, Vol. 53, No. 11, 2004, pp. 1503-1511. doi:10.1016/j.metabol.2004.04.017

[15] D. Son, N. Kunii, T. Hung, S. Sakai and S. Yamamoto, "The Metabolic Syndrome: Prevalence and Risk Factors in the Urban Population of Ho Chi Minh City," Diabetes Research and Clinical Practice, Vol. 67, No. 3, 2005, pp. 243-250. doi:10.1016/j.diabres.2004.07.014

[16] A. J. Cameron, D. J. Magliano, P. Z. Zimmet, T. Welborn and J. E. Shaw, "The Metabolic Syndrome in Australia: Prevalence Using Four Definitions," Diabetes Research and Clinical Practice, Vol. 77, No. 3, 2007, pp. 471-478. doi:10.1016/j.diabres.2007.02.002

[17] G. Buckland, J. Salas-Salvadó, E. Roure, M. Bulló and L. Serra-Majem, "Sociodemographic Risk Factors Associated with Metabolic Syndrome in a Mediterranean Population," Public Health Nutrition, Vol. 11, No. 12, 2008, pp. 1372-1378. doi:10.1017/S1368980008003492

[18] M. Kwaśniewska, D. Kaleta, E. Dziankowska-Zaborszczyk and W. Drygas, "Healthy Behaviors, Lifestyle Patterns and Sociodemographic Determinants of the Metabolic Syndrome," Central European Journal of Public Health, Vol. 17, No. 1, 2009, pp. 14-19.

[19] D. B. Carr, K. M. Utzschneider, R. L. Hull, K. Kodama, B. M. Retzlaff, J. D. Brunzell, J. B. Shofer, B. E. Fish, R. H. Knopp and S. E. Kahn, "Intraabdominal Fat Is a Major Determinant of the National Cholesterol Education Program Adult Treatment Panel III criteria for the Metabolic Syndrome," Diabetes, Vol. 53, 2004, pp. 2087-2094. doi:10.2337/diabetes.53.8.2087

[20] H. S. Park, S. W. Oh, S. Cho, W. H. Choi and Y. S. Kim, "Cardiovascular Disease and Diabetes; The Metabolic Syndrome and Associated Lifestyle Factors among South Korean Adults," International Journal of Epidemiology, Vol. 33, No. 2, 2004, pp. 328-336. doi:10.1093/ije/dyh032

[21] C. J. Billington, et al., "National Task Force on the Prevention and Treatment of Obesity. Overweight, Obesity, and Health Risk," Archives of Internal Medicine, Vol. 160, No. 7, 2000, pp. 898-904.

[22] S. M. Grundy, "National Cholesterol Education Program (NCEP) Expert Panel on Detection, Evaluation, and Treatment of High Blood Cholesterol in Adults (Adult Treatment Panel III)," Circulation, Vol. 106, 2001, pp. 3143-3421.

[23] J. B. Meigs, P. W. F. Wilson, D. M. Nathan, R. B. D'Agostino, K. Williams and S. M. Haffner, "Prevalence and Characteristics of the Metabolic Syndrome in the San Antonio Heart and Framingham Offspring Studies," Diabetes, Vol. 52, No. 8, 2003, pp. 2160-2167. 
doi:10.2337/diabetes.52.8.2160

[24] S. A. Al-Safi, "Dose Smoking Affect Blood Pressure and Heart Rate?" European Journal of Cardiovascular Nursing, Vol. 4, No. 4, 2005, pp. 286-289. doi:10.1016/j.ejcnurse.2005.03.004

[25] S. A. Al-Safi, F. H. Aboul-Enein, B. H. Aboul-Enein and B. Manuel, "Influence of Family History and Lifestyle on Blood Pressure and Heart Rate in Young Adults in Jordan," Public Health, Vol. 120, No. 11, 2006, pp. 10271032. doi:10.1016/j.puhe.2006.06.009

[26] J. Ma and M. J. Stampfer, "Body Iron and Coronary Heart Disease," Clinica Chimica Acta, Vol. 48, 2002, pp. 601-603.

[27] R. D. Bayens and M. H. Stipanuk, "Biochemical and Biophysical Aspects of Human Nutrition," Saunders Company, Philadelphia, 2000.

[28] J. L. Sullivan, "Iron and Sex Difference in Heart Disease Risk," Lancet, Vol. 1, 1981, pp. 1293-1294. doi:10.1016/S0140-6736(81)92463-6

[29] J. J. Fogli-Cawley, J. T. Dwyer, E. Saltzman, M. L. McCullough, L. M. Troy, J. B. Meigs and P. F. Jacques, "The 2005 Dietary Guidelines for Americans and Risk of the Metabolic Syndrome," American Journal of Clinical Nutrition, Vol. 86, No. 4, 2007, pp. 1193-1201.

[30] J. I. Mann, "Nutrition Recommendations for the Treatment and Prevention of Type 2 Diabetes and the Meta- bolic Syndrome: An Evidenced Based Review," Nutrition Reviews, Vol. 64, No. 9, 2006, pp. 422-427. doi:10.1111/j.1753-4887.2006.tb00227.x

[31] "Joint National Committee on the Prevention, Detection, Evaluation and Treatment of High Blood Pressure: 5th Report (JNC V)," Archives of Internal Medicine, 1993, pp. 149-153.

[32] G. Bönner, "Hyperinsulinemia, Insulin Resistance, and Hypertension," Journal of Cardiovascular Pharmacology, Vol. 24, 1994, pp. S39-S49.

[33] A. H. Lichtenstein, L. M. Ausman, S. M. Jalbert and E. J. Schaefer, "Effects of Different Forms of Dietary Hydrogenated Fats on Serum Lipoprotein Cholesterol Levels," New England Journal of Medicine, Vol. 340, No. 25, 1999, pp. 1933-1940. doi:10.1056/NEJM199906243402501

[34] F. B. Hu, J. E. Manson and W. C. Willett, "Types of Dietary Fat and Risk of Coronary Heart Disease: A Critical Review," Journal of the American College of Nutrition, Vol. 20, No. 1, 2001, pp. 5-19.

[35] R. Freire, R. A. Cardoso, I. G. A. Gimeno and R. S. G. Ferreira, "Dietary Fat Is Associated with Metabolic Syndrome in Japanese Brazilians," Diabetes Care, Vol. 28, No. 7, 2005, pp. 1779-1785. doi: $10.2337 /$ diacare.28.7.1779 